\title{
A Guideline Analysis on E-Learning Systems
}

\author{
${ }^{1}$ Dr Leelavathi Rajamanickam*, ${ }^{2}$ Kate Lam Woon Yee \\ School of Information Technology, SEGi University \\ leelavathiraj@segi.edu.my
}

\begin{abstract}
this article distinguishes and measures connections between compliance with usability guidelines and the popularity of a Web Site. A few samples of E-Learning Web Sites was studied and its usability score was recorded using an evaluation system which was developed during the study. This score was then tried against five diverse positioning frameworks utilizing Spearman's Rank connection. The consequences of these tests demonstrate a solid relationship between consistence with ease of use rules and Web webpage ubiquity. The five positioning frameworks too indicated positive relationships to each-other and to the ease of use of the locales. As conclusion, consistence with ease of guidelines could be an approach to accomplish higher Web website prevalence and guest numbers.
\end{abstract}

Keywords: e-learning webpage, websites etc.

\section{Introduction}

They have regularly recommended to customers and scholars that convenience is fundamental to any site advancement and that consistence to ease of use rules could be a pathway towards a more well-known site. However, these recommendations have been disregarded, or in the slightest respondents have not considered ease of use concentrates to be critical to their task (Scowen, Greg; Regenbrecht, 2009) [8]. Due to an absence of past research which analyses the connection amongst ease of use and prominence, persuading 
designers to put assets into ease of use considers has been troublesome. This exploration means to answer the inquiry: is there a positive connection between consistence with convenience rules and Web website fame, and assuming so how solid and significant is this relationship. Different inquiries tended to consider what ease of use rules ought to be embraced and how notoriety can best be measured (Suarez-Torrente, Conde-Clemente, Martínez, \& Juan, 2016)[10]. The discoveries of this investigation are proposed to make an establishment for promote examination concerning the impact of usability guidelines on web site's popularity.

Research Objective

The scope and objectives of this research are to find usability guidelines in E-Learning Web sites. This will determine on how many Web sites has usability guidelines which is related to this research. Besides that, we are determined to measure the correlation between popularity of a web site with a usability guideline. Do popular web sites need guidelines for the visitors? Other objective of this research is to find the effectiveness of a usability guidelines of an E-Learning Web site. Lastly, our aim is to recognize and measure connections between consistence with guidelines and five website grading system. However, it is crucial to clarify the difference between usability and accessibilities as these two are different. Accessibility could be considered a subset of usability, since usability implies accessibility (Brajnik, 2000)[2]. With all these objectives, we believe our research will not go out of track and produce the expected outcomes.

\section{Literature Review}

Looking into writing identified with this examination has addressed many inquiries, yet in addition made new inquiries that need replying. A hole in information has been recognized. Does consistence with ease of use rules associate to expanded Web website prominence? Clearly a few specialists are implying at this yet there does not have all the earmarks of being any past investigation that endeavor to answer that inquiry. The survey has additionally recognized fitting devices and strategies for directing such an examination, 
while distinguishing others that are not all that appropriate. Through reading the examination of others an unmistakable meaning of convenience has been built up and the meaning of notoriety has been refined and expressed, at all for how it is to be utilized with the end goal of this investigation. Key supporters of the field have been recognized and their discoveries mulled over. This study is conducted based on these findings and establishments.

\section{Methodology}

- $\quad$ Selection Criteria for Sites

In endeavour to limit whatever number outside impacts as could be expected under the circumstances, official Web destinations of colleges, government associations, and schools were excluded in the investigation. Since college Web locales are much of the time went by most understudies of that college, a bigger foundation would have an essentially higher guest tally. Government supported Web locales are regularly upheld by huge broadcast promoting efforts, and moreover a few destinations are an endorsed some portion of an educational modules, implying that they are utilized paying little respect to their prevalence or advance (Garavaglia \& Gaiotto, 2010)[5].

- $\quad$ Measuring Usability and Popularity

Five estimations of Web webpage ubiquity will be acquired amid the information gathering process. These will be accounted for in the outcomes. However, the most significance will be put on the quantity of connections indicating the site as found on the Google web index. Additionally, interface tally measures included are sourced from Yahoo and Del.icio.us. Both of these are incorporated to additionally bolster the Google connect tally and to distinguish if there are similitudes between these three sources. Also, the Google Page Rank and Alexa rating will be accounted for to distinguish if these have a connection with ease of use, albeit neither can be depended upon as a marker of prevalence (Kiget, Wanyembi, \& Peters, 2014)[6].

- Conducting the reviews

Ahead of schedule in the investigation it was resolved that exclusively checking on each Web website and entering reactions into an archive would be 
extremely tedious. Conceivably, this would likewise bring about errors because of the distinction in dates when the locales are checked on and the state of mind of the analyst. Computerized choices were considered; however, these were observed to need in either their capacities for testing the rules or their dependability.

- $\quad$ Creating the Review Software (WES)

Web site Evaluation System (WES) was made utilizing straightforward HTML encircling strategies. A Frameset was made with a tight band over the highest point of the page where every rule could be exhibited as an inquiry, and the rest of the program window demonstrated the site being inspected. Adjoining the inquiry were four reaction alternatives as a radio-catch gathering, and a catch utilized for presenting the reaction and moving to the following inquiry. All inquiries were composed in a way that a "Yes" reaction paralleled to consistence with the rules. A "No" reaction implied no consistence was obvious. Moreover, choices were given to specify "incomplete consistence" with a rule, or to "avoid" the rule on the off chance that it wasn't pertinent. Both of these alternatives dispensed a score of a large portion of the relative significance of the rule considered. A rule that may be skipped, for instance, is "Mark information section fields reliably." If no structures.

- Gathering data

Each of the 38 sites were checked on finished a two-day time span in August 2007. The primary creator was the main analyst engaged with the investigation and treated all sites with similar criteria for evaluating the consistence to rules. The audit was directed utilizing Internet Explorer form 7 on a Windows Vista working system. The screen determination was $1280 \mathrm{x}$ 800 in wide-screen organize on a portable workstation PC. Level looking over estimations depended on a 1024px wide determination. Download times were computed by a computerized outsider system and were measured against a benchmark of downloading the landing page on 56k modem in 10 seconds or less.

- Data analysis 
Measuring the Correlation. To quantify the quality of a connection between consistence with ease of use rules and Web site ubiquity, all information got through the review of sites was transported in into SPSS for investigation. The picked strategy for estimation connected to this information was Spearman's Rank Correlation (Spearman, 1904)[9]. This strategy was picked over the generally known Pearson Product Moment technique because of its reasonableness to non-straight, non-ordinary, ordinal information and furthermore to position factors. The quantity of connections in Google, Yahoo, and Del. icio.us are non-typical in their appropriation, and both Alexa and Google PageRank are positions. The Alexa positioning system is a turnaround arrange rank, so a connection between the Alexa Rating and convenience would be spoken to by a negative relationship coefficient.

\section{Discussion}

This investigation demonstrates that specific convenience rules are consented to oftentimes, while others are totally overlooked. What does this mean for convenience specialists? Is it conceivable that a portion of the rules distributed are too difficult to execute, or that engineers feel excessively restricted by them? Should rules that have turned out to be presence of mind be distributed by any means? Absolutely the proposal that expanded consistence with convenience rules has a solid association with expanded Web website fame is of significance to the Internet business (Ferriman, 2014)[4]. Will advance discoveries of this sort result in a higher take-up of ease of use thinks about amid Web webpage improvement? The ramifications of this finding for associations creating Web locales is whether they need to draw in more guests, at that point some exertion could be all around connected to ease of use mindfulness. For ease of use counselling organizations, this exploration calls for more investigations of a comparable sort to assist fortify the business and to manufacture more noteworthy attention to the significance of convenience and conceivable advantages.

\section{Results}


Compliance to Usability Guidelines. A goal of this investigation was to gauge the consistence with convenience rules inside a gathering of e-learning Web destinations. The consequences of the audit of 28 chose rules more than 38 Web destinations is exhibited in Appendix Table1. Two of the tried ease of use rules were incorporated to generally regularly. "Dispense with even looking over" and "utilize blended case for exposition content." Both of these rules were conformed to in 36 of the 38 destinations explored (Allen \& Seaman, 2007)[1]. Even looking over was thought to be disposed of if no flat scrollbar was shown when seeing the site at a determination 1024 pixels wide. None of the audited Web destinations totally neglected to conform to the writing content suggestions. The two destinations that did not completely go along had a few fragments of writing content that were promoted, with the lion's share being accurately designed. The minimum much of the time agreed rule was "Limit page download times," which required that the landing page of the Web website being looked into download in 10 seconds or less on a 56k modem. This was tried with the help of an outer source; Only 5 of the 38 Web destinations tried agreed to the 10 second necessity. Since this rule must be agreed to totally or not under any condition it was additionally the rule most every now and again not conformed to, with $86.8 \%$ of destinations neglecting to download in 10 seconds or less. The Correlation between Usability and Web Site Popularity. The primary goal of this examination was to gauge the quality and centrality of the connection between consistence with ease of use rules and Web webpage prevalence. Utilizing Spearman's Rank technique, the relationships between the Usability Score of each assessed Web webpage and each of the five positions that were incorporated into the information gathering process were measured. As beforehand settled, the most critical measure of notoriety with the end goal of this examination is the quantity of inbound connects to the Web webpage in Google (Docebo, 2014)[3]. The other prevalence estimations have been incorporated to additionally bolster the discoveries. The main investigation measured the connections over each of the 38 locales incorporated into the examination. When measuring the 
relationship between consistent to convenient rules with the five positioning frameworks over every one of the 48 Web locales a huge connection is obvious in all cases aside from that of Del.icio.us web-based bookmarking. The relationship between Usability Score and connections in Google is of medium quality and is noteworthy at the 0.01 level. This is the most grounded relationship between Usability Score and the positioning frameworks (Mcgee, 2017)[7]. The majority of the relationships noticeable in these three tests offer help for the speculation of this examination, that consistence with ease of use rules positively affects Web website ubiquity.

Table 1. Compliance to Usability Guidelines in 38 Websites

\begin{tabular}{|c|c|c|c|c|c|c|c|}
\hline \multirow[t]{2}{*}{ \# } & \multirow[t]{2}{*}{ Guidelines } & \multicolumn{2}{|c|}{ Complied } & \multicolumn{2}{|c|}{$\begin{array}{l}\text { Partially } \\
\text { Complied }\end{array}$} & \multicolumn{2}{|c|}{ Not Complied } \\
\hline & & \# & $\%$ & \# & $\%$ & \# & $\%$ \\
\hline 1 & $\begin{array}{l}\text { Do not display } \\
\text { unsolicited } \\
\text { windows or } \\
\text { graphics } \\
\end{array}$ & 33 & 86.8 & 4 & 10.5 & 1 & 2.6 \\
\hline 2 & $\begin{array}{l}\text { Show all major } \\
\text { options on the } \\
\text { homepage }\end{array}$ & 34 & 89.5 & 2 & 5.3 & 2 & 5.3 \\
\hline 3 & $\begin{array}{l}\text { Avoid cluttered } \\
\text { displays }\end{array}$ & 16 & 42.1 & 8 & 21.1 & 14 & 36.8 \\
\hline 4 & $\begin{array}{l}\text { Place important } \\
\text { item consistently }\end{array}$ & 21 & 55.3 & 8 & 21.1 & 9 & 23.7 \\
\hline 5 & $\begin{array}{l}\text { Elimate horizontal } \\
\text { scrolling }\end{array}$ & 36 & 94.7 & 1 & 2.6 & 1 & 2.3 \\
\hline 6 & $\begin{array}{c}\text { Use meaningful } \\
\text { link labels }\end{array}$ & 22 & 57.9 & 14 & 36.8 & 2 & 5.3 \\
\hline 7 & $\begin{array}{c}\text { Distinguish } \\
\text { required and } \\
\text { optional data entry } \\
\text { fields }\end{array}$ & 10 & 26.3 & 16 & 42.1 & 12 & 31.6 \\
\hline 8 & $\begin{array}{l}\text { Label pushbuttons } \\
\text { clearly }\end{array}$ & 18 & 47.4 & 17 & 44.7 & 3 & 7.9 \\
\hline 9 & $\begin{array}{c}\text { Organise } \\
\text { information clearly }\end{array}$ & 26 & 68.4 & 9 & 23.7 & 3 & 7.9 \\
\hline 10 & Facilitate scanning & 19 & 50.0 & 7 & 18.4 & 12 & 31.6 \\
\hline 11 & $\begin{array}{c}\text { Ensure that images } \\
\text { do not slow } \\
\text { downloads }\end{array}$ & 25 & 65.8 & 3 & 7.9 & 10 & 26.3 \\
\hline 12 & Include logos & 31 & 81.6 & 4 & 10.5 & 3 & 7.9 \\
\hline
\end{tabular}




\begin{tabular}{|c|c|c|c|c|c|c|c|}
\hline 13 & $\begin{array}{l}\text { Minimize page } \\
\text { download times }\end{array}$ & 5 & 13.2 & 0 & 0.0 & 33 & 86.8 \\
\hline 14 & $\begin{array}{c}\text { Provide text } \\
\text { quivalents for non- } \\
\text { text elements }\end{array}$ & 14 & 36.8 & 5 & 13.2 & 19 & 50.0 \\
\hline 15 & $\begin{array}{l}\text { Provide a search } \\
\text { option on every } \\
\text { page }\end{array}$ & 17 & 44.7 & 1 & 2.6 & 20 & 52.6 \\
\hline 16 & $\begin{array}{l}\text { Communicate the } \\
\text { websites value and } \\
\text { purpose }\end{array}$ & 20 & 52.6 & 12 & 31.6 & 6 & 15.8 \\
\hline 17 & $\begin{array}{c}\text { Limit homepage } \\
\text { length }\end{array}$ & 19 & 50.0 & 2 & 5.3 & 17 & 44.7 \\
\hline 18 & $\begin{array}{l}\text { Use bold text } \\
\text { sparingly }\end{array}$ & 27 & 71.1 & 3 & 7.9 & 8 & 21.1 \\
\hline 19 & $\begin{array}{l}\text { Provide feedback } \\
\text { on user's location }\end{array}$ & 14 & 36.8 & 4 & 10.5 & 20 & 52.6 \\
\hline 20 & $\begin{array}{l}\text { Provide descriptive } \\
\text { page titles }\end{array}$ & 16 & 42.1 & 9 & 23.7 & 13 & 34.2 \\
\hline 21 & $\begin{array}{c}\text { Use descriptive } \\
\text { headings liberally }\end{array}$ & 19 & 50.0 & 13 & 34.2 & 6 & 15.8 \\
\hline 22 & $\begin{array}{l}\text { Link to related } \\
\text { content }\end{array}$ & 32 & 84.2 & 3 & 7.9 & 3 & 7.9 \\
\hline 23 & Use text for links & 26 & 68.4 & 11 & 28.9 & 1 & 2.6 \\
\hline 24 & $\begin{array}{l}\text { Use black text on } \\
\text { plain, high-contrast } \\
\text { backgrounds }\end{array}$ & 23 & 60.5 & 8 & 21.1 & 7 & 18.4 \\
\hline 25 & $\begin{array}{l}\text { Use mixed-case for } \\
\text { prose text }\end{array}$ & 36 & 94.7 & 2 & 5.3 & 0 & 0.0 \\
\hline 26 & $\begin{array}{c}\text { Ensure visual } \\
\text { consistency }\end{array}$ & 27 & 71.1 & 6 & 15.8 & 5 & 13.2 \\
\hline 27 & $\begin{array}{c}\text { Format lists to ease } \\
\text { scanning }\end{array}$ & 26 & 68.4 & 4 & 10.5 & 8 & 21.1 \\
\hline 28 & $\begin{array}{c}\text { Label data entry } \\
\text { fields consistently }\end{array}$ & 24 & 63.2 & 13 & 34.2 & 1 & 2.6 \\
\hline & Mean & 23 & 59.8 & 7 & 17.8 & 9 & 22.5 \\
\hline & Median & 23 & 59.8 & 6 & 15.8 & 7 & 18.4 \\
\hline & Maximum & 36 & 94.7 & 17 & 44.7 & 33 & 86.8 \\
\hline & Minimum & 5 & 13.2 & 0 & 0.0 & 0 & 0.0 \\
\hline
\end{tabular}

\section{Conclusion}

This study represents the method in understanding about the usability guidelines increased popularity in e-learning websites. In addition, this kind of the research is essentially having to carry on to examines the correlation between the popularity and usability towards be a popular website. However, 
there has the limitation among the quality and the quantity of the sample. It need have more sample with the trusted source to ensure the method can be use in. This method of the guidelines e-learning can be help among student and client appropriate for all them to adopt. E-learning website need to be developed through the method with guidelines which can be increase the popularity.

\section{References}

Allen, I. E., \& Seaman, J. (2007). Online nation: Five years of growth in online learning. October, 1-25.

Brajnik, G. (2000). Automatic web usability evaluation: what needs to be done? 6th Conference on Human Factors and the Web, 1-14.

Docebo. (2014). E-Learning market trends and forecast: 2014 - 2016 Report. A Report by Docebo, (March), 480pp. Retrieved from

https://www.docebo.com/landing/contactform/elearning-market-trends-andforecast-2014-2016-docebo-report.pdf

Ferriman, J. (2014). The Explosive Growth of ELearning. Jeffbullas.Com, 12.

Garavaglia, A., \& Gaiotto, M. (2010). Adoption of e - learning solutions : selection criteria and recent trends, (March 2012), 1-9.

Kiget, N. K., Wanyembi, P. G., \& Peters, A. I. (2014). Evaluating Usability of E-Learning Systems in Universities. International Journal of Advanced Computer Science and Applications, 5(8), 97-102.

Mcgee, M. K. (2017). InformationWeek - E-Learning Predicted To Recover-Again, 1-2.

Scowen, Greg; Regenbrecht, H. (2009). Increased popularity through compliance with usability guidelines in e-learning Web sites. Article, 22. Spearman, C. (1904). The Proof and Measurement of Association between Two Things, 15(1), 72-101.

Suarez-Torrente, M. del C., Conde-Clemente, P., Martínez, A. B., \& Juan, A. A. (2016). Improving web user satisfaction by ensuring usability criteria 
compliance. Online Information Review, 40(2), 187-203. 